\title{
The learning styles neuromyth: when the same term means different things to different teachers
}

\section{Marietta Papadatou-Pastou ${ }^{1} \cdot$ Anna K. Touloumakos $^{1,2} \cdot$ Christina Koutouveli $^{1}$ • Alexia Barrable ${ }^{3}$ (iD}

Published online: 3 July 2020

(C) The Author(s) 2020

\begin{abstract}
Although learning styles (LS) have been recognised as a neuromyth, they remain a virtual truism within education. A point of concern is that the term LS has been used within theories that describe them using completely different notions and categorisations. This is the first empirical study to investigate education professionals' conceptualisation, as well as means of identifying and implementing LS in their classroom. A sample of 123 education professionals were administered a questionnaire consisting both closed- and open-ended questions. Responses were analysed using thematic analysis. LS were found to be mainly conceptualised within the Visual-Auditory-(Reading)-Kinaesthetic (VAK/ VARK) framework, as well as Gardner's multiple intelligences. Moreover, a lot of education professionals confused theories of learning (e.g., behavioural or cognitive theories) with LS. In terms of identifying LS, educators reported using a variety of methods, spanning from observation and everyday contact to the use of tests. The ways LS were implemented in the classroom were numerous, comprising various teaching aids, participatory techniques and motor activities. Overall, we argue that the extended use of the term LS gives the illusion of a consensus amongst educators, when a closer examination reveals that the term LS is conceptualised, identified and implemented idiosyncratically by different individuals. This study aims to be of use to pre-service and inservice teacher educators in their effort to debunk the neuromyth of LS and replace it with evidence-based practices.
\end{abstract}

Keywords Learning styles · Neuromyths · Education · Teacher Education · Continuous professional development

Alexia Barrable

a.barrable@dundee.ac.uk

1 National and Kapodistrian University of Athens, Athens, Greece

2 Panteion University of Social and Political Sciences, Athens Greece AND SKOPE Centre, University of Oxford, Oxford, UK

3 University of Dundee, Dundee, Scotland, UK 
Learning styles (LS) made an appearance in the 1950s, gained popularity in the 1970s and are still a virtual truism amongst educators (Coffield et al. 2004; Griffiths 2012). The concept behind them holds some intuitive appeal, and states that providing information through different, but individually specific, preferred modalities in instruction can improve learning. However, the concept has been heavily criticised (e.g., Krätzig and Arbuthnott 2006; Papadatou-Pastou et al. 2018; Pashler et al. 2008; Rohrer and Pashler 2012; Stahl 2002). The Centre for Educational Research and Innovation (CERI), a strand of the Organisation for Economic Cooperation and Development (OECD), has recognised and categorised LS as a neuromyth (OECD 2002). The Education Endowment Foundation, which compiles research and evidence-based practice for teachers to use, characterises the evidence for LS as 'very limited' (Education Endowment Foundation 2019, p1). Despite this widespread criticism, a great number of teachers still believe in LS (Dekker et al. 2012; Tardif et al. 2015; PapadatouPastou et al. 2017). The present study adds to the critical literature advocating against the use of LS in education, as it attempts to illustrate the fluidity of the concept and the applications of LS amongst education professionals.

A study into neuromyths in education has shown that more than $90 \%$ of teachers in the UK and Netherlands believe in the idea of a preferred mode of delivery (Dekker et al. 2012). A similar study in Portugal has found that the majority of teachers, upwards of $50 \%$, believe in instruction tailored to LS (Rato et al. 2013), whilst 91\% of Spanish teachers believe that student performance is enhanced by delivery of material in the individual's preferred LS (Ferrero et al. 2016). In the context of Greece, which is where the current study took place, studies have shown that 97\% of teachers believe in LS (Deligiannidi and Howard-Jones 2015), whilst the percentage for prospective teachers is $94 \%$ (Papadatou-Pastou et al. 2017). In addition, a review by a UK academic supports the idea that LS are still thriving in higher education (Newton 2015).

The intuitive appeal of LS rests in the reality that there are many differences amongst learners, as in special educational and additional needs (Warnock and Norwich 2005). Moreover, the fact that teachers should recognise such differences and accommodate them in their teaching is also well-documented (Jordan et al. 2009). In addition, there is now evidence to show that urging learners themselves to reflect upon their own ways of learning and develop learning strategies, such as metacognitive and self-regulation skills, can be very effective in improving learning (Dinsmore et al. 2008). What the LS literature has done, however, is take the reality that not all learners are the same, and build a quasi-scientific literature around it. A whole industry is in fact built around the identification and quantification of such LS (Coffield et al. 2004). The adoption of the LS myth has probably also proliferated as it implies that everyone can learn well, as long as the to-be-leant information matches their preferred LS.

This adoption of LS comes at a heavy cost. Some LS programmes come with a hefty price tag, potentially taking away funding from other, more useful and effective practices (Adey and Dillon 2012). The Educational Endowment Foundation (EEF 2017) reported that LS are not just an innocent misconception but can be harmful through the assignment of learners to groups or categories on the basis of a supposed LS. If individuals are categorised according to LS, the danger looms that this can lead to the assumption of fixed or rigid learning styles, which can demotivate students from adapting, let alone seeking new challenges (Education Endowment Foundation 2017). Moreover, adopting LS could limit the modes of presentation of material for certain students, leading to diminished opportunities to learn (Coffield et al. 2004). Learning Styles have indeed 
often be used in unhelpful ways by teachers, more as a way of classifying and labelling learners, rather than in a constructive way to enrich learning experiences (Franklin 2006). Furthermore, the complexity of learning can become simplified and trivialised, whilst scholarship and research literacy within education as a profession dangerously compromised (Sharp et al. 2008). The LS philosophy also encourages teachers to teach to their pupils' intellectual strengths, leaving little opportunity for students to work on their shortcomings and develop strategies to cope with them. According to a letter signed by thirty world-renowned professors of Neuroscience, Psychology and Education, 'Learning styles can create a false dimension of individuals' abilities, leading to expectations and excuses that are detrimental to learning in general' (Hood et al. 2017).

Criticism of LS as a scientific concept mainly hinges upon four different strands: firstly, the proliferation of LS models, namely the fact that there are more than 70 distinct constructs referred to as LS (Coffield et al. 2004). This results in LS being a term everyone can relate to, although they are often referring to different constructs. This lack of shared understanding is the main area of focus of this paper. Secondly, the lack of scientific basis supporting the rationale behind LS (Coffield et al. 2004; Henry 2010; Kraemer et al. 2009; Pashler et al. 2008). Thirdly, the lack of evidence to support LS use in the classroom and their potential downsides if used to guide instruction (Coffield et al. 2004; Rohrer and Pashler 2012; Stahl 2002). Finally, the lack of validity and reliability of assessment tools for LS (Adey and Dillon 2012; Papadatou-Pastou et al. 2018).

As stated above, a serious problem with the rationale behind LS is that so many different LS models have been proposed, that the term has expanded to mean different things to different people. As an illustration, in their 2004 review, Coffield et al. (2004) identified 71 of LS models, even though only 13 of them were considered to be dominant. Some of them include Honey and Mumford (1992) and Dunn and Dunn (Dunn 1990), whilst many researchers would include various instruments and theories such as Apter's Motivational Style Profile (Apter et al. 1998), Riding's Cognitive Styles Analysis (Peterson et al. 2003), Vermunt's Inventory of Learning Styles (Vermunt 1994) and Gardner's multiple intelligences (Gardner 1992). The sheer number of conflicting LS instruments and theories out there proposes a great deal of conflicting ideas about learning and the optimal techniques to facilitate it. It is not known to date which of those ideas and techniques are actually endorsed by education professionals and how, but given the proliferation of constructs covered by the term LS, it is possible that there may be confusion amongst educators with regard to the term.

Not only are the LS models numerous, but also the very notion of 'Learning Styles' lacks consistent terminology. The most commonly found terms in the literature are 'Cognitive styles', 'Learning Styles' and 'Learning Strategy' (Cassidy 2004; Curry 1990). For example, Cassidy (2004, pp. 420-421) describes an individual's cognitive style as 'a combination of psychological, cognitive and affective characteristics that facilitate each individual to interplay in his or her educational environment'. According to Dunn et al. (2002, p. 75), LS are considered to be 'a biologically and developmentally imposed set of personal characteristics that make the same teaching method effective for some and ineffective for others'. Curry (1990, p. 2) refers to learning strategy as a 'cross-situational consistency in how students approach school learning'. Most of these definitions are used interchangeably, so as to maintain the nuances between controversial theories.

When it comes to the evidence for the effectiveness of the LS model, a review of 17 studies conducted in 1993 came back with mixed results on the matching of LS and 
instructional strategies (Hayes and Allinson 1993). A more recent review of the literature reached the conclusion that there was a lack of sufficient experimental backing of LS (Pashler et al. 2008). Indeed, only a handful of systematic studies have been performed to challenge the effectiveness of the practice of delivering materials in different modalities for enhanced performance in the classroom, all of them failing to support the LS premises (Krätzig and Arbuthnott 2006; Willingham et al. 2015a, b). As an illustration, one recent experimental study investigated the effect of LS preference to performance, as related to a comprehension exercise (Rogowsky et al. 2015). After establishing each adult's preferred LS through a standardised inventory, participants were offered a verbal comprehension aptitude test in both oral and written forms. Furthermore, participants were randomly assigned to one of two groups, where they received the same material in two different modes (auditory or visual). Results showed there was no statistical significance in the relationship between learning style preference (auditory or visual) and learning aptitude. Written comprehension tests were taken by both groups, immediately and two weeks later. LS preference, delivery mode and performance in the test failed to show any statistically significant relationship.

Whilst perhaps grounded in neuroscientific findings, for example, that bimodal processing of the same information can have an additive effect (Geake 2004; Calvert et al. 2001), the emphasis should be on connectedness of brain factions, rather than separateness (Geake 2008). This premise of separateness, as promoted by LS theory, is scientifically incorrect (Adey and Dillon 2012). Moreover, evidence for the benefits for multimodal learning directly counteracts the idea that a single, preferred mode should be chosen (Kress 2000).

With regard to the last strand of criticism, the lack of validity and reliability of measurement tools, it has been shown that the psychometric properties, such as the test-retest reliability and the internal consistency of 13 popular LS tests are not sufficient (Coffield et al. 2004). This is actually to be expected given that such properties refer to the coherence and stability of a measure (reliability) as well as the appropriateness of the structure and content of a measure based on its operationalisation (validity). Thus, it would be surprising that measures of constructs that have been partially theorised and poorly operationalised present evidence for good psychometric properties. Another drawback in terms of measurement is that the LS classifications amongst individuals in classrooms are usually based on self-reports, as for example in Edmund's Learning Style Identification exercise (Reinert 1976) and in The Learning Style Profile (Keefe and Monks 1986) or based on teacher identification through observation (Graf and Liu 2009; Cassidy 2004). Marcus (1977) looked at teacher and student assessment on various areas of learning preferences, termed LS in the article. These areas included study conditions (lighting, sound, etc.), motivation styles and visual, auditory and kinaesthetic preferences. The data revealed little consensus between teacher- and self-assessment. A recent study that collected information on the LS (visual, auditory or kinaesthetic) of 199 fifth- and sixth-grade students by self-report and by teacher-report and failed to find any relationship between the two assessments (Papadatou-Pastou et al. 2018).

The current study was designed to contribute to the body of empirical evidence in relation to the first strand of criticism of LS, namely the multicurrency and ultimately the fluidity of what the term LS means and how this might translate into educational practices. No systematic investigation to date has addressed this question. More specifically, our main aim was to further and deepen our understanding of teachers' conceptualisation, identification and use (if 
any) of the LS construct in practice, drawing on their everyday experience. To achieve this, the following research questions were devised and pursued:

RQ1. What do teachers refer to by the term LS, including what are the main categories of LS they identify?

RQ2. By what means do teachers identify the LS of their students in their classroom practice?

RQ3. How do LS inform and shape teaching practice to enable students to learn?

\section{Methods}

A qualitative approach was employed in order to assess teachers' knowledge of the concept of 'Learning Styles' and map their use in practice. Whilst the richness of the method of data generation was an important guide for the selected research process, rigour was deemed equally important. To this end, a questionnaire comprising primarily open-ended questions was thought to meet the primary criteria for both breadth and depth of understanding of teachers' knowledge and practices. Open-ended questions aimed at gathering unsolicited responses on what teachers know about and how they understand, conceptualise and use what is called 'Learning Styles' in their teaching practice. Open-ended questions thus allow participants to voice their own views spontaneously (see O'Cathain and Thomas 2004), hence not fitting their views on the researchers' pre-decided and pre-determined categories, as with closed questions. Such an approach, in turn, allowed for a rich account of participants' views and a data corpus of considerable length. Findings emerged through the use of the analytic procedures outlined in thematic analysis (indicatively Frith and Gleeson 2004).

\section{Participants}

Participants were attendees of a Special Education year-long seminar, taking place in the National and Kapodistrian University of Athens, Greece. A total number of 217 participants was drawn; 123 of them formed the final sample following the inclusion criterion of having had at least 1 year of teaching experience. In particular, $56.4 \%$ of the participants had between 1 and 5 years of teaching experience, $21.8 \%$ had between 5 and 10 years of teaching experience and $21.8 \%$ had 10 years of teaching experience or more. The age range was between 20 and 52 years $(M=30,3, S D=8,26)$. The majority of the participants $(87 \%)$ worked as educators (specialisations included English, French, Music, Physics, Math, Special Ed, Theology, Philology, Early Childhood Education). The remaining $10.5 \%$ of the participants who had experience with teaching worked in social sciences (psychology and social anthropology, 6.5\%) or other professions (4\% in graphic design and interpretation); $2.5 \%$ were university students.

\section{Ethics}

The project was reviewed and received full ethical approval (Ref. No: 1616/12.03.2019) from the host institution. Participants were briefed and given the opportunity to ask questions in 
relation to the study. They were guaranteed anonymity and confidentiality; their right to withdraw at any given point with no consequences whatsoever was further made clear to them. Participation was voluntary and participants were informed that they were free to decline participation if they wished.

\section{Data generation materials}

The questionnaire was compiled by the authors of the present study and included questions on demographics (sex, age, education and teaching experience), closed questions ('Do you know of the learning styles?', with response options comprising of 'Yes', 'No', 'Don't know/Don't wish to answer' 'I have heard about LS, but do not know much'; 'Where did you learn about learning styles?' with response options comprising of 'At University', 'Through colleagues', 'Through media/press', 'Through books', 'Through scientific papers', 'Other') and openended questions ('How many learning styles exist and which are they?', 'Do you use these learning styles in your classroom / teaching? If so, in what ways? Give examples.', 'Do you think that students learn better when they receive information in their own learning style?', 'Do you think students show a preference for how they learn?', 'How do you recognise the learning style of each student?').

\section{Procedure}

Paper-and-pencil administration of the questionnaire took place during the seminar, before participants were introduced to the body of research that is critical towards LS. Completion of questionnaires lasted about 15-20 min. Prior to administration, participants were briefed, asked questions and then signed the consent forms.

\section{Data analysis}

\section{Thematic analysis}

A top-down approach, through the use of thematic analysis, was employed, following the principle that thematic analysis can be used with both deductive and inductive methodologies (Braun and Clarke 2006; Frith and Gleeson 2004). Rules for code development were devised first. In line with these rules, categories had to be (a) mutually exclusive and exhaustive - data chunks would have to fit under only one category; (b) appropriate - organised in appropriate units of analysis; (c) systematic - systematically following the analytical hierarchies deriving from the data (for example groups of themes, themes and subthemes) and (d) theoretically relevant and comprehensive - enabling the theoretical understanding on teacher's knowledge and use of LS. The mechanics of thematic analysis were judged to be useful for this exploration, and were adapted (aligning to the guidelines of Miles and Huberman 1994) so that four sequential steps were followed: (a) data reduction, (b) data display/code key, (c) identification of themes and (d) links between themes in order to address the research questions (see Table 1 for an illustration of steps (a) and (b), and Table 2 for an illustration of steps (c) and $(d))$.

Indeed, as evident from the two examples in Table 1, from respondents' quotations, we moved to data reduction (step (a)), that then directly informed the codes selected (step (b)). 
Table 1 Exemplifying steps 1 and 2 with two examples

\begin{tabular}{|c|c|}
\hline \multicolumn{2}{|l|}{ Analysis process } \\
\hline \multicolumn{2}{|c|}{$\begin{array}{l}\text { P31 "...There are many different learning styles, according to the principles of } \\
\text { multiple intelligences. These are categorized according to our basic senses: sight, } \\
\text { hearing, touch and movement..." }\end{array}$} \\
\hline $\begin{array}{l}\text { Principles of multiple intelligences } \\
\text { Caregorization of basic senses: sight, hearing, touch, movement }\end{array}$ & Step (a) data reduction \\
\hline $\begin{array}{l}\text { (1) Informed by } \mathrm{VA}(\mathrm{R}) \mathrm{K} \text { and Gardner: when a combination of at } \\
\text { least some categories from the taxonomies of } V A(R) K \text { and } \\
\text { Gardner are incorporated in the quotation. }\end{array}$ & Step (b) data display/code key \\
\hline
\end{tabular}

\begin{tabular}{|c|c|c|}
\hline \multirow{2}{*}{\multicolumn{2}{|c|}{$\begin{array}{l}\text { P51 “...Learning types have to do with whether the student is an auditory, visual, or } \\
\text { audio-visual type. One might be able to perceive the content of learning via an } \\
\text { experiential approach" } \\
\text {...” }\end{array}$}} & Example 2 \\
\hline & & \\
\hline \multicolumn{2}{|l|}{$\begin{array}{l}\text { Auditory, visual, audio-visual type. } \\
\text { Learning via en experiential approach. }\end{array}$} & Step (a) data reduction \\
\hline $\begin{array}{l}\text { (2) Informed by VA(R)K (fewer or more categories): when fewer } \\
V A(R) K \text { categories are comprised in the quotation (in this case } \\
\text { there is no reference to kinesthetic); AND when more VA }(R) K \\
\text { categories are comprised in the quotation (in this case both a } \\
\text { combination of } V A(R) K \text { categories, namely audio-visual and non } \\
V A(R) K \text { categories such as experiential approach). }\end{array}$ & Step (b) data dis & ay/code key \\
\hline
\end{tabular}

Then themes were identified (step (c)) by clarifying the properties of emergent codes and by considering them in combinations with one another. For example, in the case of the codes 'Informed by VA(R)K and Gardner', 'Informed by VA(R)K (fewer or more categories) and Gardner', the identified theme Learning Taxonomies was chosen because all of the categories identified drew from the typical taxonomies encountered in the LS discourse. This theme, in the end, comprised two more categories (for a full account, see "Analysis" section under RQ1). This iterative process was employed for each of the three RQs.

\section{Validity/inter-rater agreement}

The final coding scheme developed served as the means to explore inter-rater (inter-coder in this instance) agreement (Kirilenko and Stepchenkova 2016). One of the authors who was entirely blind to the data analysis process was invited to act as the second rater. The responses in the excel database were given to the researcher (who randomly selected $10 \%$ of them) along with the coding scheme with the instruction to assign codes to responses. The percentage of agreement between the two coders across the categories developed ranged between $79 \%$ and $100 \%$. These results indicate, at least, substantial agreement between coders (McHugh 2012).

Table 2 Exemplifying steps 3 and 4 based on examples 1 and 2

\begin{tabular}{|c|c|c|}
\hline \multicolumn{2}{|c|}{$\begin{array}{l}\text { Theme: Learning taxonomies } \\
\text { (1) Informed by VA(R)K and Gardner } \\
\text { (2) Informed by VA(R)K (fewer or more } \\
\text { categories) and Gardner }\end{array}$} & Step (c) themes identification \\
\hline $\begin{array}{l}\text { Step (d) Links between } \\
\text { themes to address the RQs }\end{array}$ & $\begin{array}{l}\text { So accord } \\
\text { equated th } \\
\text { motives), }\end{array}$ & $\begin{array}{l}\text { ig to the analysis and the codes yielded, teacher's conceptualization of LS often } \\
\text { m to learning taxonomies, learning theories and approaches, other theories (i.e. } \\
\text { nd common sense categories, or combinations of these. }\end{array}$ \\
\hline
\end{tabular}




\section{Analysis}

The analysis yielded three different coding keys, one for each of three research questions under investigation. In line with this, evidence distilled is presented here in three sections, each corresponding to one of the three research questions.

RQ1: What do teachers refer to by the term LS, including what are the main categories of LS they identify?

With regard to teachers' understanding of LS, we coded responses to those with reference to the literature and to those that just seemed to be common sense. In the first instance, codes assigned were those encountered in known LS taxonomies, learning theories and approaches (see indicatively Coffield et al. 2004; Fleming and Mills 1992). Table 3 summarises the categories that emerged through analyses. As seen, responses with reference to learning styles taxonomies and/or other taxonomies almost exclusively drew from those of VAK/VARK modalities and the corresponding learning styles, as in participant 189 and participant 46 (Barbe et al. 1979; Fleming and Baume 2006; Fleming and Mills 1992) as well as from Gardner's (1992) multiple intelligences; categories that emerged comprised either all of or

Table 3 RQ1 code key (ordered from most to least prevalent)

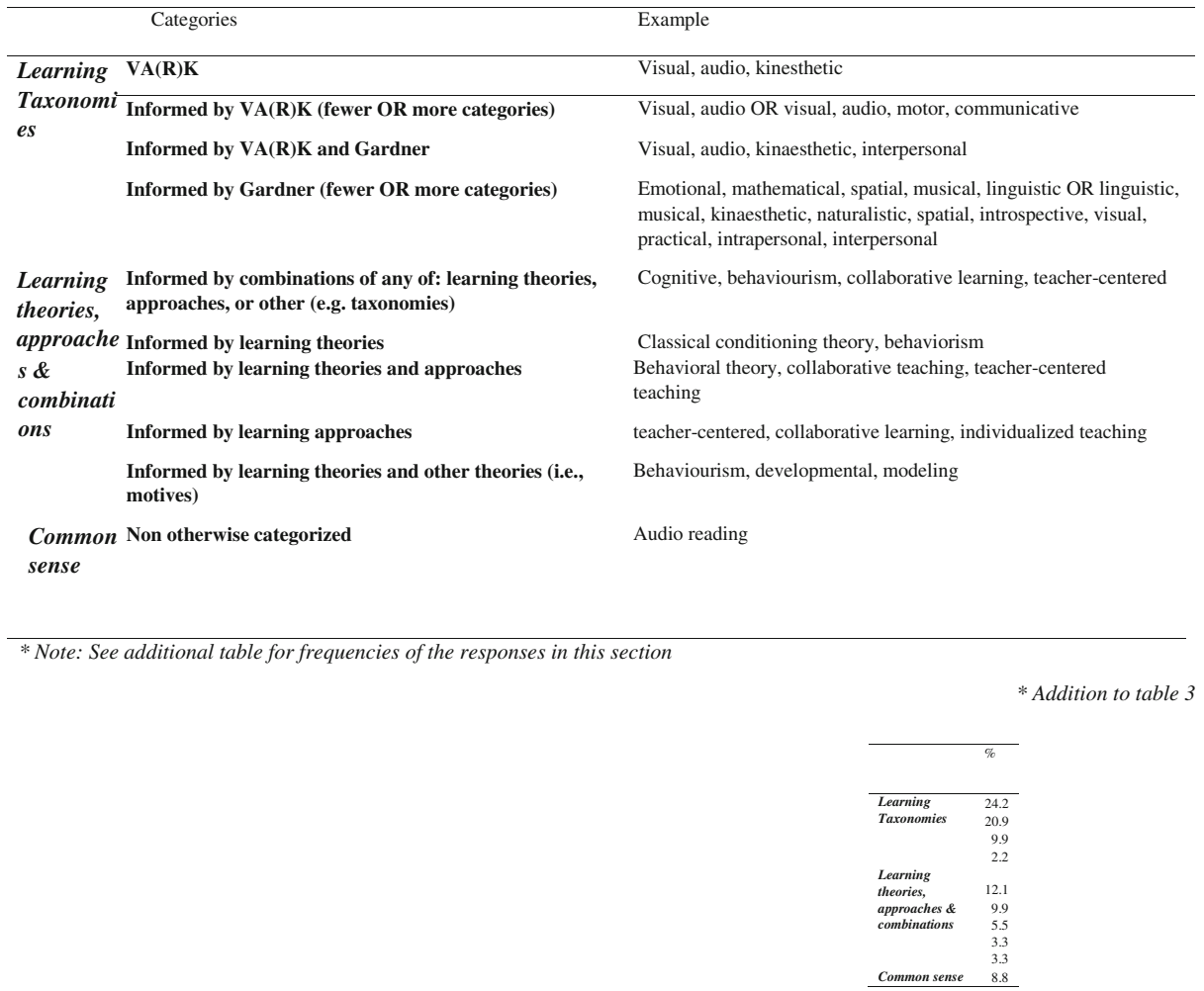


single categories of these taxonomies or combinations of categories from these two, as in participant 31 .

P189 Auditory, visual, kinaesthetic learning profile

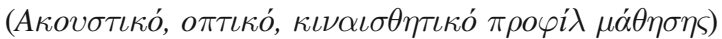

P46 I don't have knowledge of all, but of those that help us learn through our senses: visual, auditory, kinaesthetic.

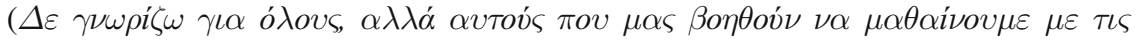
$\alpha \iota \sigma \theta \dot{\eta} \sigma \varepsilon \iota \varsigma:$ o $\pi \tau \iota \kappa o ́ \varsigma, \alpha \kappa o v \sigma \tau \iota \kappa o ́ \varsigma, \kappa \iota \nu \alpha \iota \sigma \theta \eta \tau \iota \kappa o ́ \varsigma)$

P31 There are many different learning styles, according to the principles of multiple intelligences. These are categorized according to our basic senses: sight, hearing, touch and movement.

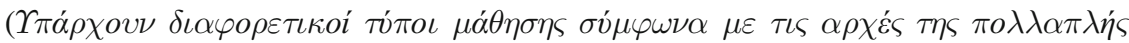

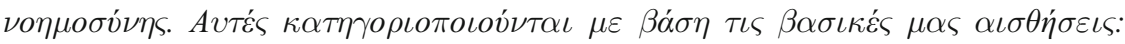
ó $\rho \alpha \sigma \eta, \alpha \kappa o \dot{\eta}, \alpha \varphi \dot{\eta}, \kappa i ́ \nu \eta \sigma \eta)$

In addition, LS were often mistaken for key aspects of different theories of learning, as seen in participant 52 (e.g. behavioural and cognitive theories), learning approaches (e.g. collaborative learning), and other theories (e.g. motivation theories), or combinations thereof, like in the case of participant 195. The few common sense categories identified (for example 'audio reading'), were those that could not fit under any of the theoretical categories mentioned, for example participant 104 .

P52 The two main learning categories are behaviourism (students associate a certain stimulus with what they have to learn each time) and cognitive (information is built upon already existing information).

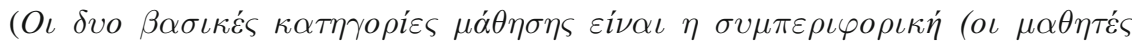

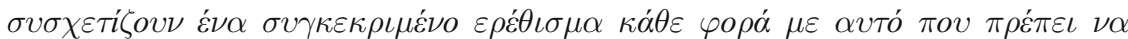

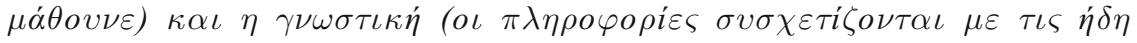
$\pi \rho o \ddot{\pi} \pi \alpha \dot{\rho} \chi o v \sigma \varepsilon \varsigma$.$) .$

P195 Behaviourist, cognitive, developmental, evolutionary ( $\Sigma v \mu \pi \varepsilon \rho \iota \varphi о \rho \iota \kappa \dot{\eta}, \gamma \nu \omega \sigma \tau \iota \kappa \eta \dot{,} \alpha \nu \alpha \pi \tau v \xi \iota \alpha \kappa \eta \dot{\eta}, \varepsilon \xi \varepsilon \lambda \iota \kappa \tau \iota \kappa \dot{\eta}$.

P104 In my opinion: 1) imitations, 2) experience 3) study (repetition) 4) through pictures

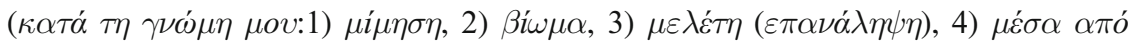

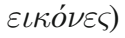

RQ2. By what means do teachers identify the LS of their students in their classroom practice?

In this second area of exploration, analysis yielded five main categories of means and approaches by which teachers identify their students' LS (see Table 4). These primarily involved some informal means such as observing (how and what) and connecting/communicating with the students (as with participant 137), but also some more formal experiential means as well as typical measurement and evaluation methods. The most prevalent responses were those involving direct observation of students' behaviour (as with Participants 43, 47, and 218, below). Teachers reported that they focus on how students actively engage with the material (i.e., process/learn, concentrate, remember, read, describe, solve problems), as with P43 for example, or respond to practices (i.e., to techniques aiming at different sensory 
Table 4 RQ2 code key (ordered from most to least prevalent, left to right and top to bottom)

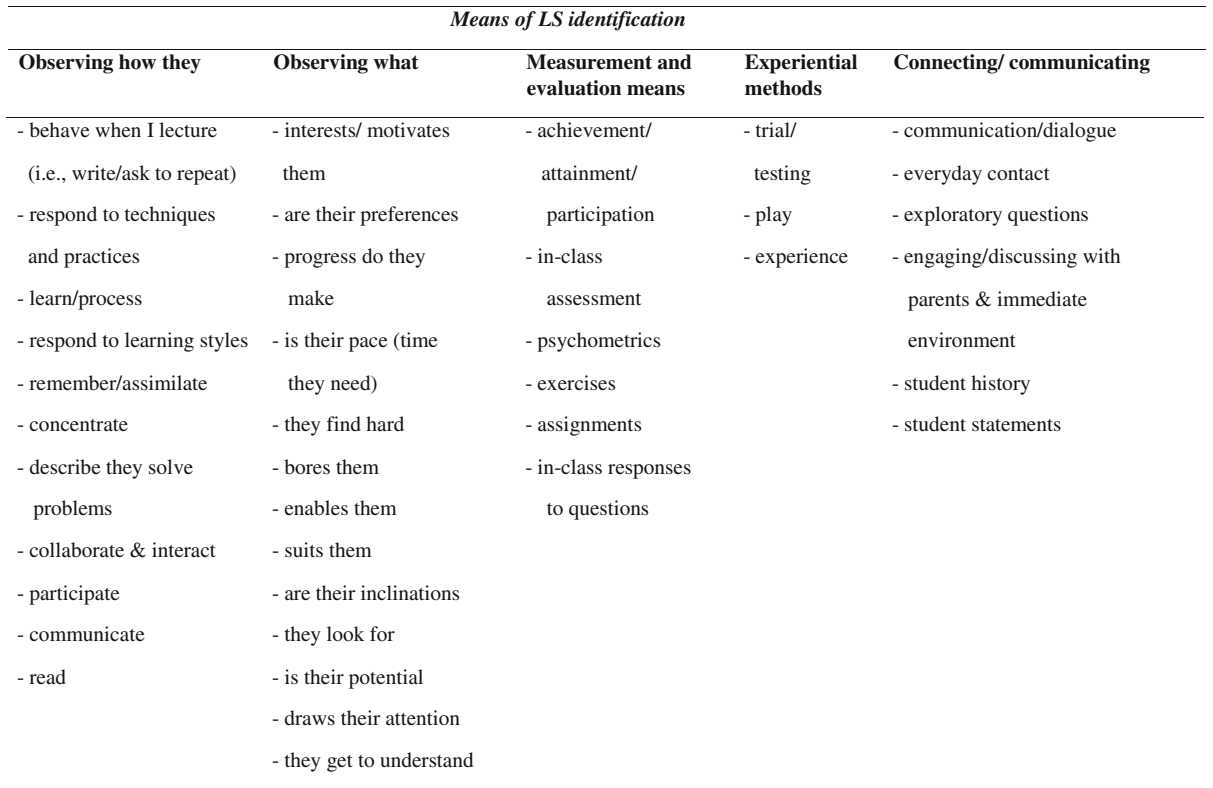

**Note: : See additional table for frequencies of the responses in this section

**Addition to Table 4

channels, or how they behave when teachers lecture), as with participants 47 and 218 for example, and how they interact with others (i.e., collaborate, participate, communicate). Similarly, teachers make notes of students of what suits, moves, bores, puzzles and enables students. Moreover, they spend time learning more about students through everyday contact and communication, as well as via exploratory questions addressed to the students and their closed ones and by taking their history.

P137 Through everyday contact and communication, you get to perceive through their work and how they respond to changes in how you teach (from traditional to more experiential)...

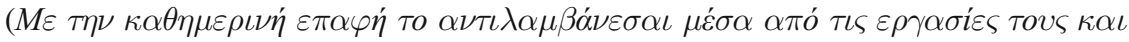

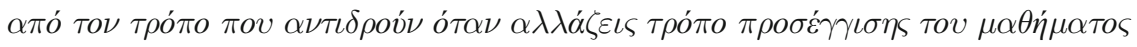

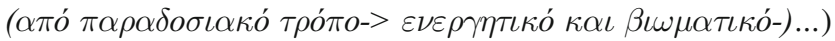

P43 Employing different exercises and different teaching aids. I observe how the students process the information, and whether s/he perceives it... 


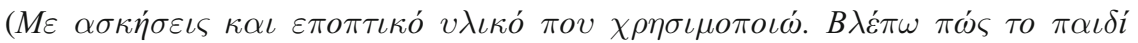

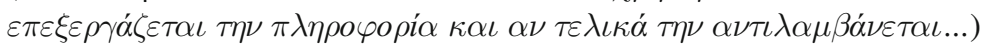

P47 Employing different teaching methods. The educator, observes (via questions) how the student responds, what s/he assimilated and what s/he learnt, what interests him/her during the lecture and if $\mathrm{s} /$ he seems interested or bored and indifferent.

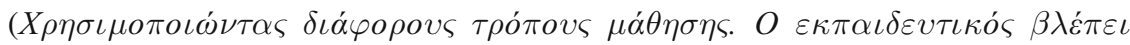

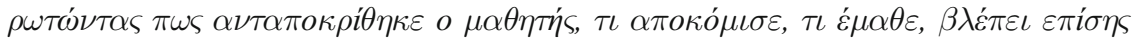

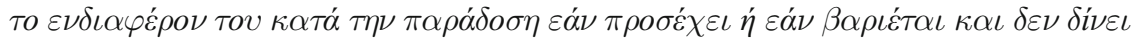

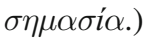

P218 From the way the student receives and assimilates information, e.g. can s/he memorize a text by just listening to it. By the interest $\mathrm{s} /$ he shows to the given activity, e.g. showing preference for motor activities and not to sedentary ones.

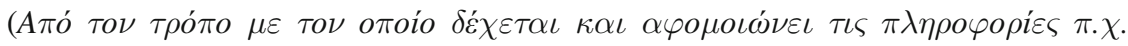

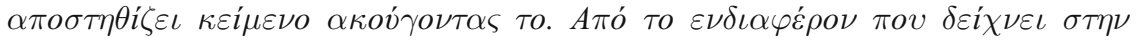

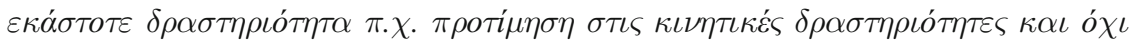
$\sigma \tau \iota \varsigma \kappa \alpha \theta \iota \sigma \tau \iota \kappa \varepsilon \dot{\varsigma}$.)

Typical measurement and evaluation approaches, from in-class assessment and participation to the use of psychometrics, and more experiential methods, such as test/trials with different approaches and play, are some additional sources of information according to teachers.

P152 Through everyday contact, you get to perceive this, through their assignments, their response when you change your approach (from traditional to more active and experiential) often the students get to ask for themselves, how they like the class, what it is that you should offer them... In addition often times you see that they are bored! and this rings a bell for you to look and find 'how would the children learn' and not what and how much they will learn! It's not just about the quantity! but the approach and the quality of the educator's teaching.

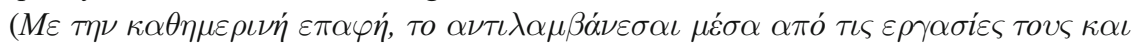

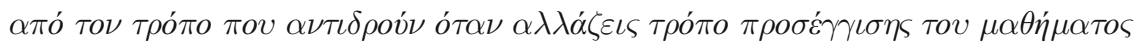

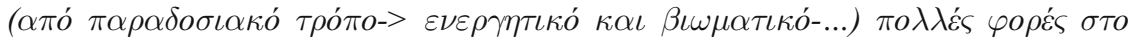

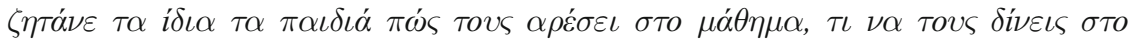

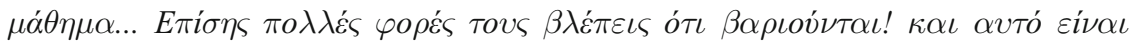

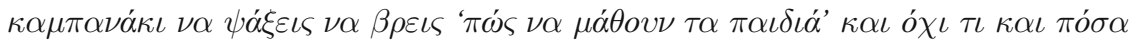

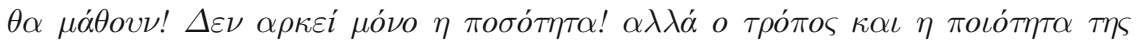
$\delta \iota \delta \alpha \sigma \kappa \alpha \lambda i \alpha \varsigma \tau o v \varepsilon \kappa \pi \alpha \iota \delta \varepsilon v \tau \iota \kappa o v$.)

RQ3. How do LS inform and shape teaching practice to enable students learn?

Five clusters of various uses of LS in teaching practices emerged through the analyses of teachers' responses (see Table 5). Unsurprisingly, and in line with the most commonly referred to categorisation of LS - namely $\mathrm{VA}(\mathrm{R}) \mathrm{K}$ presented earlier - teachers referred variably to practices that embed audiovisual aids ranging from pictures, videos, other ICT and interactive boards - as with participant 46, to even more nuanced use of aids, such as voice colouring and hand clapping (to hear the rhythm) - as with P157. In recounting the categories yielded through analysis, one realises the breadth of aids teachers call up when in practice. 
Table 5 RQ3 code key (ordered from most to least prevalent, left to right and top to bottom)

\begin{tabular}{|c|c|c|c|c|}
\hline $\begin{array}{l}\text { Audiovisual \& other } \\
\text { teaching aids }\end{array}$ & $\begin{array}{l}\text { Participatory \& other } \\
\text { methods/ techniques }\end{array}$ & Tools & $\begin{array}{l}\text { Motor activities } \\
\text { and material }\end{array}$ & Other \\
\hline - pictures & - group activities & - dialogue & - kinesthetic play & - drawing on/assessing \\
\hline - music/sound/song/ & - empirical activities & - reward-punishment & $\&$ sensory play & existing knowledge \\
\hline rhymes & - experiments & - revisions & - plasticine & - engaging in new \\
\hline - audiovisual incl. & - teacher centered & - questions \& & - dramatization & experiences \\
\hline interactive boards & teaching & answers & - motor material & - getting to know students \\
\hline - video (alone) & - project & - testing various tools & - handicraft & - using a variety of stimuli \\
\hline - graphs & (participation) & - synthesizing & - writing & \\
\hline - ICT (computers, etc.) & - visits (museums, etc.) & - offering motives & - dance & \\
\hline - narration & - interdisciplinarity & - offering extra & - use of a floor & \\
\hline - handmade cards/ & - explorative activities & sources & ruler (counting) & \\
\hline grammar rules \& & - personalized & & & \\
\hline prep & teaching & & & \\
\hline - shapes & - student centered & & & \\
\hline - drawing/sketches & teaching & & & \\
\hline - maps & - free subjects (in & & & \\
\hline - reading out loud & visual arts) & & & \\
\hline - colored text & - brainstorming & & & \\
\hline - voice colouring & - linking to previous & & & \\
\hline - time series & knowledge & & & \\
\hline - conceptual matrices & - memorizing & & & \\
\hline \multicolumn{5}{|l|}{ - rules taught via } \\
\hline \multicolumn{5}{|l|}{ - presentation } \\
\hline \multicolumn{5}{|l|}{ - board } \\
\hline \multicolumn{5}{|l|}{ - theatrical play } \\
\hline \multicolumn{5}{|l|}{ - stories } \\
\hline $\begin{array}{l}\text { - use of red ink for } \\
\text { spelling }\end{array}$ & & & & \\
\hline $\begin{array}{c}\text { - hand/finger clapping } \\
\text { (to hear rhythm) }\end{array}$ & & & & \\
\hline
\end{tabular}

***Note: See additional table for frequencies of the responses in this section

\section{**** Addition to Table 5}

\begin{tabular}{|c|c|c|c|c|}
\hline $\begin{array}{l}\text { \% } \\
\text { Audiovisual } \\
\& \\
\text { other aids }\end{array}$ & $\begin{array}{l}\% \\
\text { Participato } \\
\text { ry \& other } \\
\text { methods/ } \\
\text { techniques }\end{array}$ & $\begin{array}{l}\% \\
\text { Tools }\end{array}$ & $\begin{array}{l}\text { \% Motor } \\
\text { activities and } \\
\text { material }\end{array}$ & \% Other \\
\hline $\begin{array}{l}-9.1 \\
-5.8\end{array}$ & $\begin{array}{l}-6.7 \\
-6.3 \\
-2.4\end{array}$ & $\begin{array}{l}-4.3 \\
-4.9\end{array}$ & & -1.4 \\
\hline-5.8 & -1.4 & -2.4 & $\begin{array}{l}-1.0 \\
-1.0\end{array}$ & \\
\hline & -1.4 & $\begin{array}{l}-1.4 \\
-.9\end{array}$ & & -.5 \\
\hline-2.9 & -.9 & & $\begin{array}{r}-.5 \\
-.5\end{array}$ & -.5 \\
\hline $\begin{array}{l}-2.9 \\
-2.4\end{array}$ & $\begin{array}{r}-9 \\
-9\end{array}$ & $\begin{array}{r}-.5 \\
-.5\end{array}$ & & -.5 \\
\hline $\begin{array}{r}-1.9 \\
-1.9 \\
-.9 \\
-.9 \\
-.9 \\
-.5 \\
-.5 \\
-.5\end{array}$ & $\begin{array}{l}-.5 \\
-.5 \\
-.5 \\
-.5 \\
-.5\end{array}$ & & & \\
\hline & -.5 & & & \\
\hline $\begin{array}{l}-.5 \\
-.5 \\
-.5 \\
-.5 \\
-.5\end{array}$ & & & & \\
\hline-.5 & & & & \\
\hline
\end{tabular}


P46 They are used not compartmentalised but in combination. For example a video or a power-point with embedded sound...

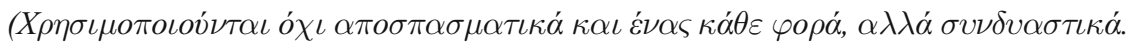

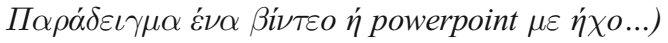

P157 Auditory: creating poems through rhythm or rhymes. Maybe by combining with hand-finger clapping, visual: with sketches, graphs. When needed, I make them right there and then to make the transition or the progression of what I want to student to perceive obvious.

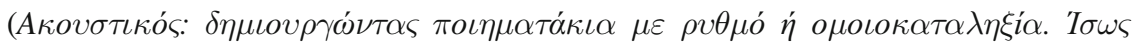

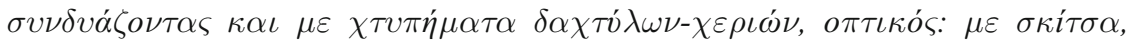

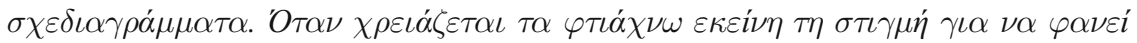

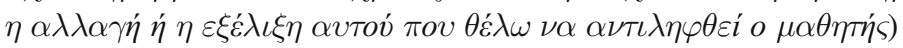

The use of a wide range of motor materials and activities was reported too (ranging from the use of plasticine and floor rulers to kinaesthetic/sensory play and dramatisation) - as with participant 162. Similarly, participatory and other methods (ranging from group and other explorative activities, experiments, projects, visits, to personalised teaching, interdisciplinarity, and teacher- and student-centred teaching) was an additional category that emerged based on teachers' responses; an example is that of participant 186. Prevalent tools reported included the use of reinforcement and punishment, Q \& As, dialogues and revisions and some approaches not fitting under the previous clusters, including using various stimuli and drawing on/ assessing existing knowledge.

P162 ...for the kinaesthetic type I will use means such as plasticine, we will engage in interactive play, we will dance.

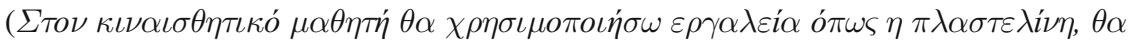

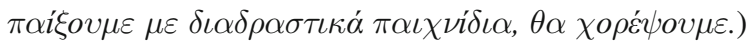

P186 Group activities, experiential method, interdisciplinary approach, project,

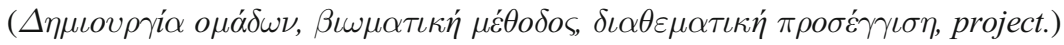

Figure 1 features the interrelation suggested here between the three parts as well as the diverse patterns of themes that emerged through the analyses.

\section{Discussion}

The present study aimed to investigate, in an empirical fashion, how the term LS is conceptualised by education professionals as well as how LS are identified and implemented within the classroom. To date, only anecdotal accounts exist supporting that LS is a term used flexibly, resulting in it representing different ideas and definitions for different people and subsequently resulting in varying ways of practically implementing the LS theory. In order to empirically investigate this question for the first time, a qualitative approach was employed, which gave rich data coming from 123 educators. Thematic analysis was used for the analysis of participants' responses.

According to our analysis, teachers in our sample responded comfortably to our questions about LS, as indicated by the very few instances of missing responses, as well as the richness of the responses, suggesting a familiarity with the term. This familiarity, however, did not translate to a uniform view of LS. This is not to say that there have not been patterns in their 


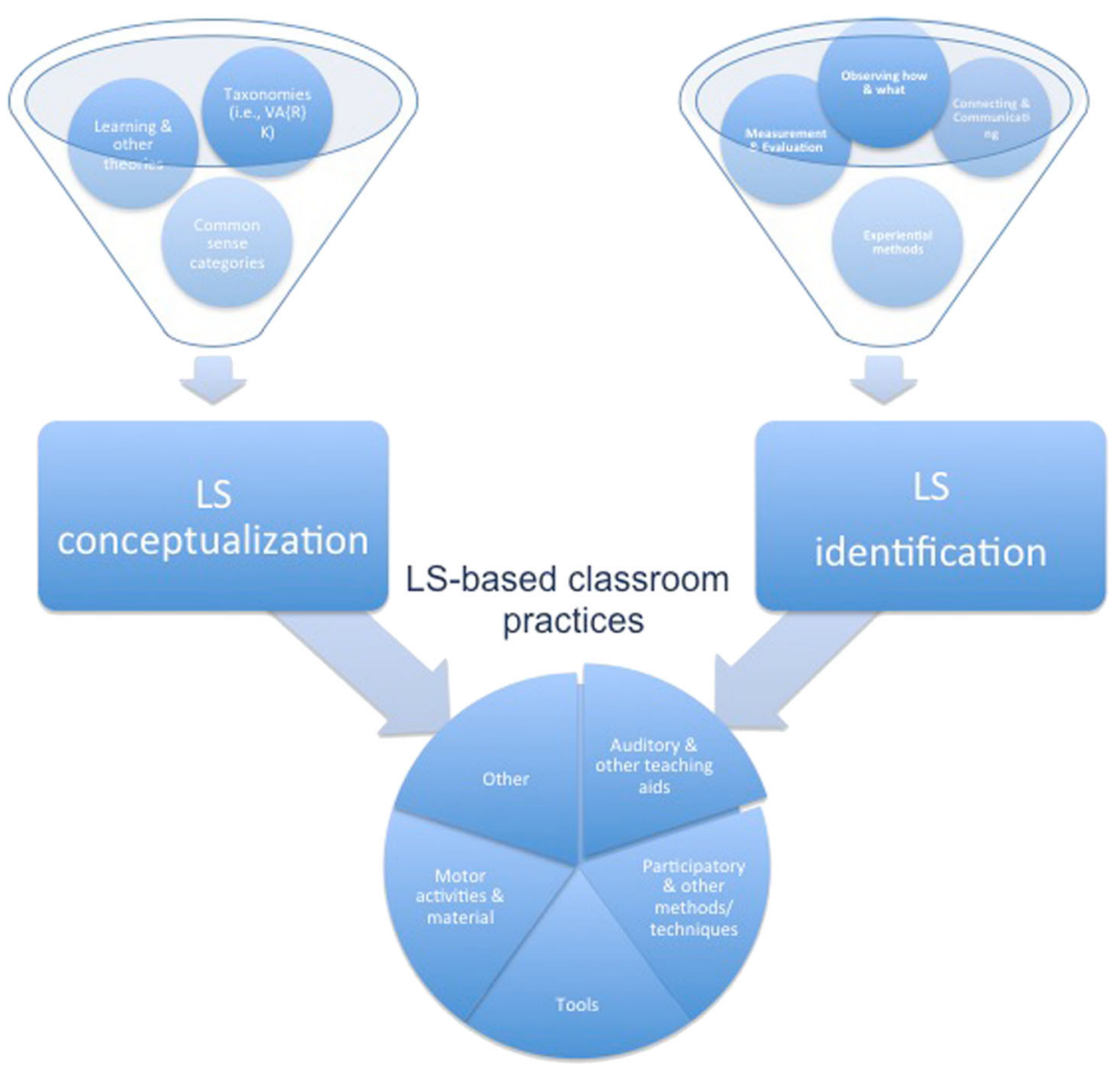

Fig. 1 Schematic representation of the interrelation between the three parts: LS conceptualisation, identification and LS-based classroom practices

responses. In fact, we did encounter a good amount of responses indicating that teachers conceptualise and understand LS primarily within the Visual-Auditory-(Reading)-Kinaesthetic (VAK/VARK) modalities framework (Barbe et al. 1979; Fleming and Baume 2006; Fleming and Mills 1992), and secondarily within Gardner's multiple intelligences theory (1992). Of note, the second richest repository of ideas respondents drew on in their conceptualisation of LS included theories of learning, other theories (for example motivation, developmental theories) and elements of learning approaches. However, and whilst known categories from aforementioned taxonomies, theories and approaches were identified in many cases, more were the respondents that selectively chose and combined such categories. Therefore, on the one hand, the overlap between theories was considerable (especially learning theories, learning approaches and LS), which suggests that teachers confused LS for theories and approaches, such as behaviourism and collaborative learning; on the other hand, the confusion within theories, approaches and models was considerable: teachers would not uniformly draw on one theory or model but rather 'mix and match'. Arguably, categories presented so far corroborate the considerable expansion of the LS term to other diverse and distinct theoretical constructs. This finding, together with the stretch of the construct to fit what are only 'common sense' 
categories, suggests an entirely unsystematised view of LS. In other words, the term seems to mean different things to different people.

This article, therefore, not only adds to the criticism of LS as a term that applies to diverse and unrelated constructs (Coffield et al. 2004) but also aims to give a clear snapshot of the various theorisations and misconceptions that exist in relation to them. This is useful for both researchers and practitioners, and has implications for teacher education, both pre- and inservice. Having an idea of the current misconceptions that exist can inform teacher education programmes in how to tackle the issues of neuromyths, in this case the persistent use of LS in teaching practice.

As teachers further offer a detailed account of methods they have in place for identifying students' LS, spanning from observation of how the students perform different task (e.g., concentrate, behave during a lecture) and observation of what interests, suits, motivates or bores students, to using in-class assessment and exercises, teacher education can focus on providing appropriate evidence-based strategies that can replace LS. Findings show that some teachers also make use of experiential methods, such as play and trial/testing, or rely on their everyday communication with the students or the students' caretakers. Evidence on how teachers conceptualise and identify LS inform in turn the implementation of strategies and techniques teachers mobilise to teach what they consider an LS-informed classroom. In particular, a host of audiovisual and teaching aids (including interactive boards, computers, grammar rules and prep, to voice colouring) were recounted by participants, as well as participatory techniques (including experiments, group activities and visits), typical learning tools (such as dialogue and Q\&A sessions), motor activities (including sensory play, dance or use of floor ruler) or other methods such as engaging in new experiences. The methods recounted by teachers in our sample exceed dramatically what one would have expected to see in terms of numbers and variability of responses had the teachers focused on catering students LS based on one or two specific LS models.

Of note here is that the evidence generated through this research suggests a linear and strong link between LS conceptualisation and identification and LS-informed teaching practices. The responses identified in the question about LS teaching practices, aligned, in some cases perfectly, with the way teachers mentioned they conceptualise LS as well as go about identifying LS in their practice. Whilst the responses that the participants gave in each of the questions addressing the three research questions were congruent with each other, consistency was not reached amongst participants in terms of LS conceptualisation and LS in practice. In other words, whilst there was within-subject agreement, the conceptualisation between subjects was hugely divergent.

Furthermore, the extended use of the term LS gives the illusion of a consensus amongst education professionals. However, a closer examination reveals that the term LS is not only conceptualised idiosyncratically by different teachers, but that LS are also identified and implemented in that way. To conclude, different educators mean different things when they talk about and work with LS. This lack of true consensus may be attributed to the number of different approaches that are all considered to describe LS. The fluidity of the concept of LS both in terms of conceptualisation and implementation adds to the other criticisms that LS are facing: lack of a scientific rationale behind the development of the LD theory(ies), lack of empirical evidence for their effectiveness and lack of valid and reliable measurement tools.

The present study relied exclusively on the self-reports of teachers. This is a limitation to our study with regard to how they implement LS within their classrooms that could be addressed in the future by direct classroom observations. Future studies could, moreover, take 
this exploration forward in different directions. First, a study with a small number of interviewees could be used to solidify the coding scheme and offer a respondent validation purposes. Second, a replication study with substantially large samples of teachers could provide evidence on how many of them conceptualise, identify and/or use LS in the ways that were identified here, hence enhancing the credibility of our results through triangulation. Third, a survey incorporating elements of existing LS taxonomies including the ones found here could be used to investigate which of these elements teachers know and how much they know about them. The two latter studies would be beneficial in helping to plan the provision of targeted continuous professional development for teachers, aimed at resolving misconceptions and providing evidence-based approaches to teaching differentiation.

Based on our findings, we would like to strongly support previously voiced recommendations for the adoption of evidence-based approaches within educational contexts and the abandonment of practices that not only lack evidence, but additionally may be harmful to learners (Geake 2008; Lilienfeld et al. 2011). Indeed, adoption of neuromyths in education, of which LS is one, contains many pitfalls. With only limited resources in education, neuromyths could be diverting such resources away from more valuable and evidence-based practices (Pasquinelli 2012; Sylvan and Christodoulou 2010). In addition to financial resources, the adoption of neuromyths wastes time and energy (Willingham et al. 2015a, b). It further diverts teachers from evidence-based practices they could employ in their teaching. Last, adoption of neuromyths reveals a lack of critical and research skills.

A concerted effort has been made in the last several years to identify teachers' misconceptions and debunk such neuromyths within educational practice. A series of articles have explored the issue of teacher misinformation and the prevalence of neuromyths amongst teachers (Dekker et al. 2012; Deligiannidi and Howard-Jones 2015; Ferrero et al. 2016) as well as trainee teachers (Howard-Jones et al. 2009; Papadatou-Pastou et al. 2017), as presented in the introduction. Whilst this has been taking place, articles in the mainstream media have also attempted to debunk LS and dissuade teachers from using non-evidenced-based practices in classroom (Henry 2010). Moreover, several proposals have been made by researchers and teacher educators on incorporating neuroscience and cognitive psychology modules within formal teacher education (Goswami 2004; Hille 2011; Papadatou-Pastou et al. 2017). In addition to debunking neuromyths, such as LS, providing teachers with alternative, but evidence-based pedagogies, could be of use. Such pedagogies could include 'learning to learn' or 'learning skills' interventions that focus on metacognitive skills and self-regulation of learning. These techniques have been shown to be effective and have a high impact on student attainment in several systematic reviews and meta-analyses (Bangert-Drowns et al. 2004; Hattie et al. 1996; Sitzmann and Ely 2011).

In conclusion, this is the first study to empirically investigate how LS are conceptualised, identified as well as applied within the classroom. It showed in a robust way that the concept of LS is understood differently by different educators and that the LS of the students are identified by their teachers in varied ways. Furthermore, our study showcased that the implementation of LS theory in the classroom rests upon the educator, resulting in a multiple of different ways in which LS are implemented. This level of variability in responses as well as in the emerged themes across the three research questions in this study suggests that the concept of LS can fit so much that renders its theoretical delineation impossible and its meaningful use in practice the least questionable. Therefore, the present study adds to the growing body of evidence that is sceptical of the LS literature (Coffield et al. 2004; Curry 1990; Franklin 2006; PapadatouPastou et al. 2018; Pashler et al. 2008), as it showed that the term LS is used in an idiosyncratic 
way by educators, resulting in a lack of consensus amongst them on what LS actually mean and how they should be identified and implemented. This article should provide a starting point for professionals working within Initial Teacher Education, as well as in continuous professional development in order to selectively target misconceptions in relation to LS, whilst at the same time providing evidence-based alternatives for differentiation. We hereby add to the many voices that support the abandonment of the use of LS in education.

Open Access This article is licensed under a Creative Commons Attribution 4.0 International License, which permits use, sharing, adaptation, distribution and reproduction in any medium or format, as long as you give appropriate credit to the original author(s) and the source, provide a link to the Creative Commons licence, and indicate if changes were made. The images or other third party material in this article are included in the article's Creative Commons licence, unless indicated otherwise in a credit line to the material. If material is not included in the article's Creative Commons licence and your intended use is not permitted by statutory regulation or exceeds the permitted use, you will need to obtain permission directly from the copyright holder. To view a copy of this licence, visit http://creativecommons.org/licenses/by/4.0/.

\section{References}

Adey, P., \& Dillon, J. (2012). Bad education: Debunking myths in education. Maidenhead, UK: McGraw-Hill Education.

Apter, M. J., Mallows, R., \& Williams, S. (1998). The development of the motivational style profile. Personality and Individual Differences, 24(1), 7-18. https://doi.org/10.1016/S0191-8869(97)00148-7.

Bangert-Drowns, R. L., Hurley, M. M., \& Wilkinson, B. (2004). The effects of school-based writing-to-learn interventions on academic achievement: A meta-analysis. Review of Educational Research, 74(1), 29-58. https://doi.org/10.3102/00346543074001029.

Barbe, W. B., Swassing, R. H., \& Milone, M. N. (1979). Teaching through modality strengths: Concepts and practices (Reprinted ed.). Columbus, $\mathrm{OH}$ : Zaner-Bloser.

Braun, V., \& Clarke, V. (2006). Using thematic analysis in psychology. Qualitative Research in Psychology, 3(2), 77-101. https://doi.org/10.1191/1478088706qp063oa.

Calvert, G. A., Hansen, P. C., Iversen, S. D., \& Brammer, M. J. (2001). Detection of audio-visual integration sites in humans by application of electrophysiological criteria to the BOLD effect. Neuroimage, 14(2), 427-438. https://doi.org/10.1006/nimg.2001.0812.

Cassidy, S. (2004). Learning styles: An overview of theories, models, and measures. Educational Psychology, 24(4), 419-444. https://doi.org/10.1080/0144341042000228834.

Coffield, F., Moseley, D., Hall, E., \& Ecclestone, K. (2004). Learning styles and pedagogy in post-16 learning: A systematic and critical review. Learning and Skills Research Centre London, UK. http://www.voced.edu. au/content/ngv:13692. Retrieved April 12, 2019.

Curry, L. (1990). A critique of the research on learning styles. Educational Leadership, 48(2), 50-56.

Dekker, S., Lee, N. C., Howard-Jones, P., \& Jolles, J. (2012). Neuromyths in education: Prevalence and predictors of misconceptions among teachers. Frontiers in Psychology, 3, 429. https://doi.org/10.3389 /fpsyg.2012.00429.

Deligiannidi, K., \& Howard-Jones, P. (2015). The neuroscience literacy of teachers in Greece. Procedia-Social and Behavioral Sciences, 174, 3909-3915. https://doi.org/10.1016/j.sbspro.2015.01.1133.

Dinsmore, D. L., Alexander, P. A., \& Loughlin, S. M. (2008). Focusing the conceptual lens on metacognition, self-regulation, and self-regulated learning. Educational Psychology Review, 20(4), 391-409. https://doi. org/10.1007/s10648-008-9083-6.

Dunn, R. (1990). Understanding the Dunn and Dunn learning styles model and the need for individual diagnosis and prescription. Reading, Writing, and Learning Disabilities, 6(3), 223-247. https://doi.org/10.1080 $/ 0748763900060303$.

Dunn, R., Beaudry, J. S., \& Klavas, A. (2002). Survey of research on learning styles. California Journal of Science Education, 2(2), 75-98.

Education Endowment Foundation (2017). Learning Styles. https://educationendowmentfoundation.org. uk/evidence-summaries/teaching-learning-toolkit/learning-styles/. Retrieved April 12, 2019. 
Educational Endowment Foundation (2019). Teaching and learning toolkit: Learning Styles available at https://educationendowmentfoundation.org.uk/pdf/generate/?u=https://educationendowmentfoundation.org. $\mathrm{uk} / \mathrm{pdf} / \mathrm{toolkit} /$ id=136\&t=Teaching\%20and\%20Learning\%20Toolkitande $=136 \& \mathrm{~s}$

Ferrero, M., Garaizar, P., \& Vadillo, M. A. (2016). Neuromyths in education: Prevalence among Spanish teachers and an exploration of cross-cultural variation. Frontiers in Human Neuroscience, 10, 496. https://doi.org/10.3389/fnhum.2016.00496.

Fleming, N., \& Baume, D. (2006). Learning Styles again: VARKing up the right tree! Educational Developments, 7, 4-7 http://www.johnsilverio.com/EDUI6702/Fleming_VARK_learningstyles.pdf.

Fleming, N. D., \& Mills, C. (1992). Helping students understand how they learn. The teaching professor, 7(4). Madison, Wisconsin, USA: Magma Publications.

Franklin, S. (2006). VAKing out learning styles - why the notion of 'learning styles' is unhelpful to teachers. Education, 3-13, 34(1), 81-87. https://doi.org/10.1080/03004270500507644.

Frith, H., \& Gleeson, K. (2004). Clothing and embodiment: men managing body image and appearance. Psychology of Men \& Masculinity, 5(1), 40-48. https://doi.org/10.1037/1524-9220.5.1.40.

Gardner, H. (1992). Multiple intelligences (Vol. 5, p. 56). Minnesota: Minnesota Center for Arts Education.

Geake, J. (2004). How children's brains think: Not left or right but both together. Education 3-13, 32(3), 65-72. https://doi.org/10.1080/03004270485200351.

Geake, J. (2008). Neuromythologies in education. Educational Research, 50(2), 123-133. https://doi. org/10.1080/00131880802082518.

Goswami, U. (2004). Neuroscience and education. British Journal of Educational Psychology, 74(Pt 1), 1-14. https://doi.org/10.1348/000709904322848798.

Graf, S., \& Liu, T.-C. (2009). Supporting teachers in identifying students' learning styles in learning management systems: An automatic student modelling approach. Journal of Educational Technology \& Society, 12(4), 3-14.

Griffiths, C. (2012). Learning styles: Traversing the quagmire. In S. Mercer, S. Ryan, \& M. Williams (Eds.), Psychology for Language Learning (pp. 151-168). Hampshire, UK: Palgrave MacMillan.

Hattie, J., Biggs, J., \& Purdie, N. (1996). Effects of learning skills interventions on student learning: A metaanalysis. Review of Educational Research, 66(2), 99-136. https://doi.org/10.2307/1170605.

Hayes, J., \& Allinson, C. W. (1993). Matching learning style and instructional strategy: An application of the person environment interaction paradigm. Perceptual and Motor Skills, 76(1), 63-79. https://doi. org/10.2466/pms.1993.76.1.63.

Henry, J. (2010). Professor pans' learning style' teaching method. The Telegraph. http://www.telegraph.co. uk/news/uknews/1558822/Professor-pans-learning-style-teaching-method.html. Retrieved April 12,2019.

Hille, K. (2011). Bringing research into educational practice: Lessons learned. Mind, Brain, and Education, 5(2), 63-70. https://doi.org/10.1111/j.1751-228X.2011.01111.x.

Honey, P., \& Mumford, A. (1992). The manual of learning styles. Berkshire: Peter Honey Publications.

Hood, B., Howard-Jones, P., Laurillard, D., Bishop, D., Coffield, F., Frith, D. U., et al. (2017). No evidence to back idea of learning styles. The Guardian. https://www.theguardian.com/education/2017/mar/12/noevidence-to-back-idea-of-learning-styles. Retrieved April 12, 2019

Howard-Jones, P. A., Franey, L., Mashmoushi, R. \& Liao, Y.-C. (2009) The neuroscience literacy of trainee teachers, at the British Educational Research Association Annual Conference (University of Manchester) Retrieved April 12, 2019, http://www.leeds.ac.uk/educol/documents/185140.pdf.

Jordan, A., Schwartz, E., \& McGhie-Richmond, D. (2009). Preparing teachers for inclusive classrooms. Teaching and Teacher Education, 25(4), 535-542. https://doi.org/10.1016/j.tate.2009.02.010.

Keefe, J. W., \& Monks, J. S. (1986). Learning Style profile: Examiner's manual. Reston, VA: Reston Publishing.

Kirilenko, A. P., \& Stepchenkova, S. (2016). Inter-coder agreement in one-to-many classification: Fuzzy kappa. PloS one, 11(3), e0149787. https://doi.org/10.1371/journal.pone.0149787.

Kraemer, D. J., Rosenberg, L. M., \& Thompson-Schill, S. L. (2009). The neural correlates of visual and verbal cognitive styles. Journal of Neuroscience, 29(12), 3792-3798. https://doi.org/10.1523/JNEUROSCI.4635-08.2009.

Krätzig, G. P., \& Arbuthnott, K. D. (2006). Perceptual learning style and learning proficiency: A test of the hypothesis. Journal of Educational Psychology, 98(1), 238-246. https://doi.org/10.1037/00220663.98.1.238.

Kress, G. (2000). Multimodality: Challenges to Thinking About Language. TESOL Quarterly, 34(2), 337-340. https://doi.org/10.2307/3587959.

Lilienfeld, S. O., Lynn, S. J., Ruscio, J., \& Beyerstein, B. L. (2011). 50 great myths of popular psychology: Shattering widespread misconceptions about human behavior. Chichester, UK: John Wiley \& Sons.

Marcus, L. (1977). How teachers view student learning styles. NASSP Bulletin, 61(408), 112-114.

McHugh, M. L. (2012). Interrater reliability: the kappa statistic. Biochemia medica: 22(3), 276-282, DOI: https://doi.org/10.11613/BM.2012.031

Miles, M. B., \& Huberman, A. M. (1994). Qualitative data analysis: An expanded sourcebook. Thousand Oaks: Sage. 
Newton, P. M. (2015). The Learning Styles myth is thriving in Higher Education. Frontiers in Psychology, 6 , 1908. https://doi.org/10.3389/fpsyg.2015.01908.

O'Cathain, A., \& Thomas, K. J. (2004). "Any other comments?" Open questions on questionnaires-a bane or a bonus to research? BMC Medical Research Methodology, 4(1), 25. https://doi.org/10.1186/1471-2288-4-25.

OECD (2002). There is a visual, auditive and a haptic type of learning. http://www.oecd. org/education/ceri/neuromyth3.htm. Accessed 15 April 2019.

Papadatou-Pastou, M., Haliou, E., \& Vlachos, F. (2017). Brain knowledge and the prevalence of neuromyths among prospective teachers in Greece. Frontiers in Psychology, 8, 804. https://doi.org/10.3389 /fpsyg.2017.00804.

Papadatou-Pastou, M., Gritzali, M., \& Barrable, A. (2018). The Learning Styles educational neuromyth: Lack of agreement between teachers' judgments, self-assessment, and students' intelligence. Frontiers in Education, 3, 105. https://doi.org/10.3389/feduc.2018.00105.

Pashler, H., McDaniel, M., Rohrer, D., \& Bjork, R. (2008). Learning styles: Concepts and evidence. Psychological Science in the Public Interest, 9(3), 105-119. https://doi.org/10.1111/j.15396053.2009.01038.x.

Pasquinelli, E. (2012). Neuromyths: Why do they exist and persist? Mind, Brain, and Education, 6(2), 89-96. https://doi.org/10.1111/j.1751-228X.2012.01141.x.

Peterson, E. R., Deary, I. J., \& Austin, E. J. (2003). The reliability of Riding's cognitive style analysis test. Personality and Individual Differences, 34(5), 881-891. https://doi.org/10.1016/S0191-8869(02)00116-2.

Rato, J. R., Abreu, A. M., \& Castro-Caldas, A. (2013). Neuromyths in education: What is fact and what is fiction for Portuguese teachers? Educational Research, 55(4), 441-453. https://doi.org/10.1080 /00131881.2013.844947.

Reinert, H. (1976). One picture is worth a thousand words? Not necessarily! The Modern Language Journal, 60(4), 160-168. https://doi.org/10.2307/326308.

Rogowsky, B. A., Calhoun, B. M., \& Tallal, P. (2015). Matching learning style to instructional method: Effects on comprehension. Journal of Educational Psychology, 107(1), 64-78. https://doi.org/10.1037/a0037478.

Rohrer, D., \& Pashler, H. (2012). Learning Styles: Where's the evidence? Online Submission, 46(7), 634-635. https://doi.org/10.1111/j.1365-2923.2012.04273.x.

Sharp, J. G., Bowker, R., \& Byrne, J. (2008). VAK or VAK-uous? Towards the trivialisation of learning and the death of scholarship. Research Papers in Education, 23(3), 293-314. https://doi.org/10.1080 $/ 02671520701755416$.

Sitzmann, T., \& Ely, K. (2011). A meta-analysis of self-regulated learning in work-related training and educational attainment: What we know and where we need to go. Psychological Bulletin, 137(3), 421442. https://doi.org/10.1037/a0022777.

Stahl, S. A. (2002). Different strokes for different folks? In L. Abbeduto (Ed.), Taking sides: Clashing on controversial issues in educational psychology. Guilford, CT: McGraw-Hill.

Sylvan, L. J., \& Christodoulou, J. A. (2010). Understanding the role of neuroscience in brain based products: A guide for educators and consumers. Mind, Brain, and Education, 4(1), 1-7. https://doi.org/10.1111/j.1751228X.2009.01077.x.

Tardif, E., Doudin, P. A., \& Meylan, N. (2015). Neuromyths among teachers and student teachers. Mind, Brain, and Education, 9(1), 50-59. https://doi.org/10.1111/mbe.12070.

Vermunt, J. D. (1994). Inventory of Learning Styles (ILS) in higher education. Tilburg: University of Tilburg. https://www.researchgate.net/profile/Eappen_John2/post/Where_can_I_find_the_Vermunts_Inventory_of_ Learning_Styles_ILS_English_Version_for_my_Research/attachment/59d63f0879197b807799b8a8/AS\% 3 A426123554234372\%401478607180503/download/Vermunt\%27s+ILS-+120+scoring+Key.pdf. Retrieved 12 April 2019.

Warnock, M., \& Norwich, B. (2005). Special educational needs: A new look. London: Continuum Publishing.

Willingham, D. T., Hughes, E. M., \& Dobolyi, D. G. (2015a). The scientific status of learning styles theories. Teaching of Psychology, 42(3), 266-271.

Willingham, D. T., Hughes, E. M., \& Dobolyi, D. G. (2015b). The scientific status of learning styles theories. Teaching of Psychology, 42(3), 266-271. https://doi.org/10.1177/0098628315589505.

Marietta Papadatou-Pastou

Marietta Papadatou-Pastou is a neuropsychologist working as an Assistant Professor at the Department of Primary Education of the National and Kapodistrian University of Athens. Her research focuses on handedness and laterality, with an emphasis on the use of meta-analysis and functional transracial Doppler ultrasound. She is 
also interested in neuromyths in education and in developing an online support system using evidence-based techniques to support students in Higher Education who experience mild to moderate psychological and academic skills difficulties (MePlusMe). Some of her latest publications, which are relevant to Psychology of Education, include:

Papadatou-Pastou, M., Gritzali, M., \& Barrable, A. (2018). Educational neuromyths using the case of learning styles: Lack of agreement between teachers' judgments of their students' Learning Styles, self-assessed Learning Styles, and students' intelligence. Frontiers in Education: Educational Psychology, Doi: https://doi.org/10.3389 /feduc.2018.00105

Ntolka, E., \& Papadatou-Pastou, M. (2018). Right-handers have negligibly higher IQ scores than left-handers: Systematic review and meta-analyses. Neuroscience \& Biobehavioral Reviews, 84,376-393. Doi: https://doi. org/10.1016/j.neubiorev.2017.08.007

Barrable, A., Papadatou-Pastou, M., \& Tzotzoli, P. (2018). Supporting mental health, wellbeing and study skills in higher education: An online intervention system. International Journal of Mental Health Systems, 12(1), 54. Doi: https://doi.org/10.1186/s13033-018-0233-z

Goozée, R., Papadatou-Pastou, M., Barley, E., Haddad, M., \& Tzotzoli, P. (2018). Survey to inform the development of an online support system for higher education Students. Health, 10(03), 351. Doi: https:// doi.org/https://doi.org/10.4236/health.2018.103028

Markou^, P., Ahtam, B., \& Papadatou-Pastou, M. (2017). Elevated levels of atypical handedness in autism: Meta-analyses. Neuropsychology Review, 1-26. Doi: https://doi.org/10.1007/s11065-017-9354-4

Papadatou-Pastou, M., Haliou, E., \& Vlachos, F. (2017). Brain knowledge and the prevalence of neuromyths among prospective teachers in Greece. Frontiers in Psychology: Educational Psychology, 8, 804. Doi: https://doi.org/10.3389/fpsyg.2017.00804

Papadatou-Pastou, M., Goozee, R., Payne, E., Barrable, A., \& Tzotzoli, P. (2017). A review of web-based support systems for students in higher education. International Journal of Mental Health Systems, 11(1), 59. Doi: https://doi.org/10.1186/s13033-017-0165-z

Papadatou-Pastou, M., \& Sáfár, A. (2016). Handedness prevalence in the deaf: Meta-analyses. Neuroscience and Biobehavioral Reviews. 60, 98-114. Doi: https://doi.org/10.1016/j.neubiorev.2015.11.013

Touloumakos, A. K., Goozée, R., Papadatou-Pastou, M., Barley, E., Haddad, M., \& Tzotzoli, P. (2016). Online support system for students in higher education: Proof-of-concept study. Digital Health, 2, 2055207616655012. Doi: https://doi.org/10.1177/2055207616655012

Papadatou-Pastou, M., Goozée, R., Barley, E. A., Haddad, M., \& Tzotzoli, P. (2015). Online intervention, 'MePlusMe', supporting mood, wellbeing, study skills, and everyday functioning in students in higher education: A protocol for a feasibility study. BMC Pilot and Feasibility Studies, 1(1), 1-10. Doi: https://doi.org/10.1186/s40814-015-0029-8

Papadatou-Pastou, M., \& Tomprou, D. M. (2015). Intelligence and handedness: Meta-analyses of studies on intellectually disabled, typically developing and gifted individuals. Neuroscience and Biobehavioural Reviews, 56, 151-156, Doi: https://doi.org/10.1016/j.neubiorev.2015.06.017

Kyriakides, L., Creemers, B. P. M., Papastylianou, D., \& Papadatou-Pastou, M. (2014). Improving the school learning environment to reduce bullying: An experimental study. Scandinavian Journal of Educational Research, 58(4), 453-478. Doi: https://doi.org/10.1080/00313831.2013.773556

Gilmore, C., \& Papadatou-Pastou, M. (2009). Patterns of individual differences in conceptual understanding and arithmetical skill: A meta-analysis. Special Issue of Mathematical Thinking and Learning on "Young Children's Understanding and Application of the Addition-Subtraction Inverse Principle”, 11(1), 25-40. Doi: https://doi.org/10.1080/10986060802583923

Papadatou-Pastou, M., Martin, M., Munafò, M. R., \& Jones, G. V. (2008). Sex differences in left-handedness: A meta-analysis of 144 studies, Psychological Bulletin, 134(5), 677-99. Doi: https://doi.org/10.1037/a0012814

Anna K. Touloumakos

Anna K. Touloumakos currenlty works with children in institutional care (and matched controls) investigating their language development, including communication skills. She is interested in understanding how trauma, for example from neglect or abuse, typical amongst children in institutional care, affects development as well as in the role the 'home' environment plays in supporting development. Her latest publications include:

Touloumakos, A.K., Goozée R., Papadatou-Pastou, M., Barley, E., Haddad, M., \& Tzotzoli, P. (2016).Online support system for students in higher education: Proof of concept study, Digital Health, 2,2055207616655012, doi: 10.1177/2055207616655012.

Giotsa, A. \& Touloumakos, A.K. (2016). They accept me, they accept me not: Psychometric properties of the Greek version of Child Parental Acceptance-Rejection Questionnaire -Short Form, Journal of Family Issues, 37(9), 1226-1243. (first published online on July 30th 2014), doi: $10.1177 / 0192513 X 14543851$. 
Giotsa, A., \& Touloumakos, A.K. (2015) Parental Perceptions About the Behavior of Their Children (PECC): The psychometric traits of PECC Instrument, in M. Machado \& F. Machado, (eds), New paths for acceptance: Opening awareness in interpersonal acceptance-rejection, Boca Raton, FL: Brown Walker Press.

Giotsa, A. \& Touloumakos, A.K. (2014). Perceived Parental Acceptance and Psychological Adjustment: The moderating role of parental power and prestige among Greek pre-adolescents, Cross Cultural Research, 48(3), 250-258, doi:10.1177/1069397114528300.

Christina Koutouveli

Christina Koutouveli is a teacher working at elementary education whilst reading for an MSc on Special Education. She is currently participating in an ongoing research on children aged 5 to 7 years old investigating their language development, and she is further involved in a meta-analysis on the development of handedness.

Alexia Barrable

Alexia Barrable works in Initial Teacher Education at the University of Dundee. Her research interests centre around the meaningful application of research evidence to teacher education and teaching, and especially in relation to early childhood and outdoor education. Her latest publications include:

Barrable, A., \& Arvanitis, A. (2019). Flourishing in the forest: Looking at Forest School through a selfdetermination theory lens. Journal of Outdoor and Environmental Education, 22(1), 39-55. https://oi. org/10.1007/s42322-018-0018-5

Barrable, A. (2019). Refocusing environmental education in the early years: A brief introduction to a pedagogy for connection. Education Sciences, 9(1), [61]. https://doi.org/10.3390/educsci9010061

Barrable, A., (2019). The case for nature connectedness as a distinct goal of early childhood education, International Journal of Early Childhood Environmental Education, 6 (2)

Barrable, A., \& Lakin, L. (in press). Nature relatedness in student teachers, perceived competence and willingness to teach outdoors: An empirical study, Journal of Adventure Education and Outdoor Learning https://doi.org/10.1080/14729679.2019.1609999

Papadatou-Pastou, M., Gritzal, M., \& Barrable, A. (2018). The Learning Styles educational neuromyth: Lack of agreement between teachers' judgments, self-assessment, and students' intelligence. Frontiers in Education, 3, 1-5. [105]. https://doi.org/10.3389/feduc.2018.00105

Springer Nature remains neutral with regard to jurisdictional claims in published maps and institutional affiliations. 